\title{
ROLE OF DEXMEDETOMIDINE AND CLONIDINE AS ADJUVANTS WITH ROPIVACAINE IN EPIDURAL ANAESTHESIA- A COMPARATIVE STUDY
}

\author{
B. S. B. Mallika1, K. V. Siva Prasad ${ }^{2}$
}

${ }_{1}^{1}$ Assistant Professor, Department of Pharmacology, Rangaraya Medical College, Kakinada, Andhra Pradesh, India.

2Professor, Department of Pharmacology, Rangaraya Medical College, Kakinada, Andhra Pradesh, India.

\begin{abstract}
BACKGROUND
ABSTRACT

There is a need for regional anaesthesia which offers quicker onset and prolonged duration with less adverse effects to the patients. Since a long time efforts are being made to find out a better adjuvant in regional anaesthesia. This study was undertaken to compare the analgesic and sedative effects of Dexmedetomidine and Clonidine when used as a neuraxial adjuvant to ropivacaine in patients undergoing lower abdominal surgeries.
\end{abstract}

\section{MATERIALS AND METHODS}

A randomized, prospective, double-blind, comparative study was done in 60 patients of ASA I/II grade (American Society of Anesthesiologists), undergoing lower abdominal surgeries. Randomization was carried out and the patients were divided into two groups: ropivacaine + clonidine (Group A) and ropivacaine + dexmedetomidine (Group B), consisting of 30 in each. Group A was given admixture of $19 \mathrm{ml}$ of $0.75 \%$ ropivacaine and $1 \mathrm{ml}$ of $2 \mu \mathrm{g} / \mathrm{kg}$ of clonidine while Group B was given $19 \mathrm{ml}$ of $0.75 \%$ epidural ropivacaine and $1 \mathrm{ml}$ of $1.5 \mu \mathrm{g} / \mathrm{kg}$ of dexmedetomidine. Onset of sensory block, onset of motor block, duration of motor block, duration of analgesia, degree of sedation and side effects were observed. The data was statistically analysed using statistical package for social science (SPSS) version 17 for windows.

\section{RESULTS}

The study results showed that the mean time of onset of sensory and motor blockade in Group B is less when compared to Group A. The duration of motor blockade and the duration of analgesia was significantly higher in Group B compared to Group A. These differences are statistically significant. In terms of safety, the hemodynamic parameters and side effects are same in both the groups.

\section{CONCLUSION}

Dexmedetomidine proved to be a better neuraxial adjuvant in providing early onset of analgesia, prolonged analgesia in the postoperative period and adequate sedation when compared to Clonidine.

\section{KEY WORDS}

Clonidine, Dexmedetomidine, Ropivacaine, Epidural Anaesthesia

HOW TO CITE THIS ARTICLE: Mallika BSB, Prasad KVS. Role of dexmedetomidine and clonidine as adjuvants with ropivacaine in epidural anaesthesia- a comparative study. J. Evolution Med. Dent. Sci. 2019;8(11):754-757, DOI: 10.14260/jemds/2019/166

\section{BACKGROUND}

Pain is defined as "an unpleasant sensory and emotional experience associated with actual or potential tissue damage or described in terms of such damage" by International association for the study of Pain. Surgical pain affects patients in the intraoperative and postoperative period in terms of deleterious physical and psychological effects apart from an agonizing sensory experience associated with it. Postoperative analgesia play a pivotal role and is aimed to prevent these effects.(1) The cost of general anaesthesia, the skill and specialized equipment needed for its administration coupled with an indifferent supply of anaesthetic gases and

'Financial or Other Competing Interest': None.

Submission 21-01-2019, Peer Review 27-02-2019,

Acceptance 06-03-2019, Published 18-03-2019.

Corresponding Author:

Dr. K. V. Siva Prasad,

Professor, Department of Pharmacology,

Opp. Government Gen. Hospital,

Rangaraya Medical College,

Kakinada-533001,

Andhra Pradesh, India.

E-mail: sivakpt@gmail.com

DOI: $10.14260 /$ jemds $/ 2019 / 166$ drugs and lack of monitoring equipment especially in peripheral areas in a country like India made Regional Anaesthetic techniques as choice because they can be easily administered and are relatively inexpensive.(2) Among the regional anaesthetic techniques subarachnoid block has gained immense popularity in surgeries involving lower abdominal and orthopaedic procedures. ${ }^{(3)}$

Neuraxial anaesthesia is one of the widely used procedure. It includes generation of nerve block by using spinal and epidural techniques, where anaesthesia and analgesia is achieved by single injection, bolus or by continuous infusion of the drug. Neuraxial adjuvants increase the speed of onset of neural blockade and prolong the duration of analgesia, in addition to their dose sparing effects.(4) Adverse effects caused by high doses of a single anaesthetic drug can be overcome by adding these agents. $\alpha-2$ adrenergic agonists when used as adjuvants in regional anaesthesia, have both analgesic and sedative properties. $(5,6)$ Dexmedetomidine is a selective $\alpha_{2}$ adrenergic agonist and when compared to clonidine it has eight times higher affinity. Several studies have proved that the anaesthetic and the analgesic requirement is reduced by the use of $\alpha$ blockers as adjuvants.(7) The present study was done to compare the analgesic and sedative effects of these drugs when used epidurally as neuraxial adjuvants with ropivacaine. 


\section{MATERIALS \& METHODS}

A randomized, prospective, double-blind study was done to compare the efficacy of epidural ropivacaine with clonidine and epidural ropivacaine with dexmedetomidine in patients undergoing lower abdominal surgeries. This study was carried out in the Department of Anaesthesiology, Government General Hospital, Rangaraya medical college, Kakinada. The study was approved by the institutional ethical committee. The protocol of the study was reviewed and approved by Dr. NTR University of Health Sciences, Vijayawada.

After obtaining informed consent from patients, 60 patients of ASA (American Society of Anesthesiologists) grade I and II between the ages of 20 and 50 years were enrolled for the study. Patients with ASA Grade $\geq$ III, having any contraindications to regional anaesthetics, those with known sensitivity to local anaesthetics and patients with local infection at the site of injection were excluded from the study. Sample size was taken for convenience.

A total number of 60 patients, 30 in each group were selected for the study. Based on a computer-generated code the patients were randomly allocated to one of the following two treatment groups in a double blinded fashion. An anaesthesia technician who was unaware of the proceedings was asked to prepare the drug syringes. The study medications as per the method were coded and given by the anaesthetist during the surgery. At the end of the study the code of the two drugs was open for analysis. The Anaesthetist was also advised to inform and to open the study drug code in case of any untoward effect.

\section{Group A}

$\mathrm{n}=30$ : Consists of patients in whom $1 \mathrm{ml}$ of Inj. Clonidine (2 $\mu \mathrm{g} / \mathrm{kg}$ ) is added to $19 \mathrm{ml}$ of $0.75 \%$ Ropivacaine, administered epidurally.

\section{Group B}

$\mathrm{n}=30$ : Consists of patients in whom $1 \mathrm{ml}$ of inj. Dexmedetomidine $(1.5 \mu \mathrm{g})$ is added to $19 \mathrm{ml}$ of $0.75 \%$ Ropivacaine, administered epidurally.

During preoperative visit patient's history, general and systemic examination were done. Demographic data like age, sex, height and weight were recorded. During the preanaesthetic checkup, VAS (visual analogue scale) Numeric pain distress scale was explained to all patients using a $10 \mathrm{~cm}$ scale.

Patients were premedicated with $0.05 \mathrm{mg} / \mathrm{kg}$ of Inj. Midazolam, 45-60 mins prior to procedure. Initially, before starting the surgery vitals such as pulse rate, blood pressure and SpO2 were recorded. All the patients were given 10 $\mathrm{ml} / \mathrm{kg}$ of Lactated Ringer's solution through 18/16 G IV cannula. Epidural block was done with 18 gauge Touhy needle and catheter was secured 3-4 cm into epidural space. A test dose of $3 \mathrm{ml}$ of $2 \%$ lignocaine with $15 \mu \mathrm{gm}$ of adrenaline was injected and after 5 mins if there was no adverse reaction for the test dose the study drugs were administered.

The time of injection was recorded as zero hour in both the groups and the following parameters were observed intraoperatively and post operatively: Onset of sensory blockade at T10 level, Onset of motor blockade, Duration of motor blockade which is taken as the time from injection to return of power to BROMAGE Grade 0, Degree of sedation (Wilson sedation scale), Duration of analgesia and Side effects. To check the sensory level bilateral pin-prick method was used. A Bromage scale $(0=$ full movement, $1=$ unable to raise extended leg, can bend knee, 2 = unable to bend knee, can flex ankle, 3 = no movement) was used to measure the motor blockade. Grading of sedation was evaluated by Wilson's sedation scale (1-Fully awake and oriented, 2Drowsy, 3-Eyes closed but responsive to command, 4-Eyes closed but responsive to mild physical stimulation (earlobe tug) and 5-Eyes closed but unresponsive to mild physical stimulation). Sedation scores were recorded just before the initiation of surgery and thereafter every 20 minutes during the surgical procedure.

Cardio-respiratory parameters like blood pressure, pulse rate, $\mathrm{SPO}_{2}$ were monitored continuously till the end of procedure. If the systolic arterial pressure falling more than $20 \% \mathrm{mmHg}$, it was termed as hypotension and was treated with inj. Mephentermine 3-6 mg in bolus doses and if the heart rate $<50$ beats/min it was termed as bradycardia and was treated with $0.3-0.6 \mathrm{mg}$ of inj. Atropine. As per the patient's requirement, intravenous fluids were given. During the surgical procedure side effects like nausea, vomiting, bradycardia, hypotension, respiratory depression, dry mouth and shivering were noted in both groups.

At the end of surgery, the patient was shifted to postoperative ward and all the vital parameters were recorded at regular intervals. Visual Analogue Scale score was noted postoperatively. The duration of analgesia was calculated from the time of completion of epidural injection to the time of rescue analgesic administered in postoperative period or when Visual Analgesia Scale score of 4 was reached. Pain was managed with top up dose of Ropivacaine post operatively. Duration of analgesia and pain relief in Group A and Group B were recorded. At the end of study all data was compiled and statistically analysed using Statistical Package for Social Science (SPSS) version 17 for windows, presented in tabular form as MEAN $\pm \mathrm{SD}$. The analysis is done between two study groups by unpaired " $\mathrm{t}$ " test. $\mathrm{P}$ value was calculated and the value $<0.05$ was considered statistically significant.

\section{RESULTS}

Of the sixty patients, 30 belong to Group A [ $19 \mathrm{ml}$ of $0.75 \%$ Ropivacaine with $1 \mathrm{ml}$ of Inj. Clonidine $(2 \mu \mathrm{g} / \mathrm{kg})]$ and 30 patients belong to Group B [19 $\mathrm{ml}$ of $0.75 \%$ Ropivacaine with $1 \mathrm{ml}$ of inj. Dexmedetomidine $(1.5 \mu \mathrm{g} / \mathrm{kg})]$. Results were analysed in both groups based on various parameters such as onset of sensory blockade, onset of motor blockade, duration of motor blockade, total duration of analgesia, degree of sedation and side effects.

\begin{tabular}{|c|c|}
\hline Group & Mean \pm SD (Mins.) \\
\hline A & $9.50 \pm 1.85$ \\
\hline B & $7.96 \pm 1.60$ \\
\hline P value & $<0.01$ \\
\hline
\end{tabular}

Table 1. Time of Onset of Sensory Block in Each Group

The mean duration of onset of sensory block at T10 was earlier in Dexmedetomidine group (Group B).

\begin{tabular}{|c|c|}
\hline Group & Mean \pm SD (mins) \\
\hline A & $20.86 \pm 2.93$ \\
\hline B & $18.53 \pm 2.52$ \\
\hline p-Value & $<0.01$ \\
\hline
\end{tabular}

Table 2. Time of Onset of Motor Block in Each Group

Modified Bromage scale 3 was achieved earlier in Group B, thus the mean duration of onset of motor block is quicker in Dexmedetomidine (Group B). 


\begin{tabular}{|c|c|}
\hline Group & Mean \pm SD (Mins.) \\
\hline A & $230.66 \pm 27.56$ \\
\hline B & $253.33 \pm 27.92$ \\
\hline p-Value & $<0.01$ \\
\hline \multicolumn{2}{|c|}{ Table 3. Duration of Motor Block in Each Group } \\
\hline \multicolumn{2}{|c|}{ The mean duration of motor blockade was more in } \\
Dexmedetomidine group (Group B)
\end{tabular}

\begin{tabular}{|c|c|}
\hline Group & Mean \pm SD (Mins.) \\
\hline A & $311.66 \pm 42.02$ \\
\hline B & $394.00 \pm 54.68$ \\
\hline p-Value & $<0.001$ \\
\hline
\end{tabular}

Table 4. Total Duration of Analgesia of Each Group

Duration of analgesia is taken from the time of completion of epidural Injection to the time of rescue analgesic administration in the postoperative period. The mean duration of analgesia is more in Dexmedetomidine group (Group B). The statistical analysis by unpaired ' $t$ ' test showed that there is a highly statistically significant difference between the two groups.

\begin{tabular}{|c|c|c|c|}
\hline Groups & $\begin{array}{c}\text { Pulse rate } \\
\text { (Mean + SD) }\end{array}$ & $\begin{array}{c}\text { Systolic B.P. } \\
\text { (Mean + SD) }\end{array}$ & $\begin{array}{c}\text { Diastolic B.P. } \\
\text { (Mean + SD) }\end{array}$ \\
\hline A & $74.8+3.56$ & $107.52+8.49$ & $70.68+5.55$ \\
\hline B & $73.04+4.87$ & $105.44+8.34$ & $71.28+6.31$ \\
\hline p-Value & NS & NS & NS \\
\hline Table 5. Pulse, Systolic BP and Diastolic BP of Each Group \\
\hline \multicolumn{4}{|c|}{ NS = Not significant } \\
\hline \multicolumn{3}{|c|}{$\begin{array}{r}\text { In both the groups there is no statistically significant } \\
\text { difference in the hemodynamic variables. (P>0.05) }\end{array}$} \\
\hline
\end{tabular}

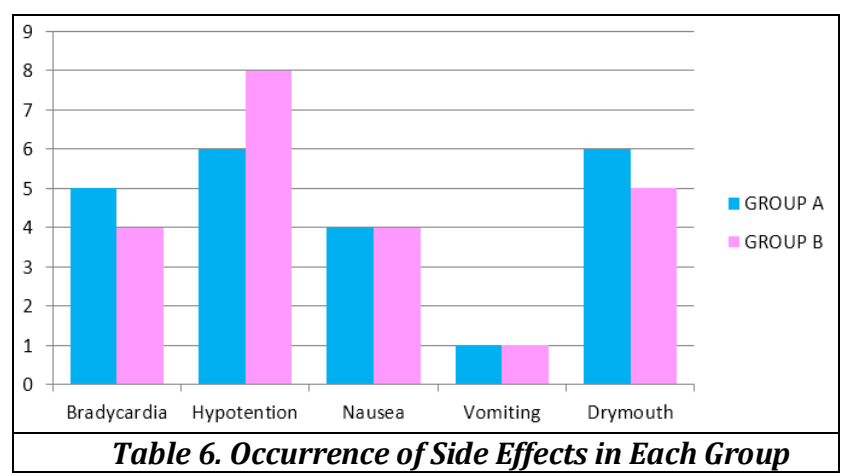

The side effects most commonly observed are hypotension, bradycardia \& dry mouth, which are seen commonly with regional anaesthesia. Respiratory depression is not observed in any patient belonging to either group. Nausea, vomiting were observed in patient of either group equally. There is no statistically significant difference between both the groups.

\begin{tabular}{|c|c|c|}
\hline Sedation Score & Group A (n=30) & Group B (n=30) \\
\hline 1 & 15 & 3 \\
\hline 2 & 6 & 9 \\
\hline 3 & 9 & 18 \\
\hline 4 & 0 & 0 \\
\hline 5 & 0 & 0 \\
\hline \multicolumn{2}{|c|}{ Table 7. Sedation Scores in Each Group }
\end{tabular}

The level of sedation was assessed in both groups by Wilson's Sedation Scale. 3/5 Wilson sedation scores were significantly higher in Dexmedetomidine group (Group-B)

\section{DISCUSSION}

Use of neuraxial adjuvants have an advantage of reduced requirement of dose and rapid onset of action of local anaesthetics, quicker onset of both sensory and motor blockade, long duration of analgesia which extends into the post-operative period and stable hemodynamic parameters. Patient compliance can be improved by reducing the adverse effects associated with high dose of a single local anaesthetic agent. These properties had made them as effective adjuvants in regional anaesthesia.(8) They include sodium bicarbonate, vasoconstrictors, opioids, $\alpha 2$ agonists, N-methyl- D- aspartate (NMDA) antagonists, cholinergic agonists and $\gamma$ - amino butyric acid (GABA) receptor agonists. Opioids when used as adjuvants cause few side-effects such as respiratory depression, urinary retention and pruritis, hence evaluation is under process to replace them with $\alpha-2$ agonists. $\alpha-2$ agonists act by altering transmembrane potential and ion conductance, thus cause hyperpolarisation of nerves in the brainstem (Locus coeruleus). $\left({ }^{9,10}\right)$ Epidural administration of these drugs is associated with analgesia, anxiolysis, sedation and hypnosis. Among the $\alpha 2$ agonists, Clonidine is being widely used since past 10 years and the advent of dexmedetomidine may offer more advantage as adjuvant in regional anaesthesia.

The present study was undertaken to compare the analgesic efficacy as well as sedation effects of $\alpha-2$ agonists. The study results have shown that good sedation level was achieved during the surgical procedure and the duration of analgesia was prolonged into the post-operative period with addition of either $1.5 \mu \mathrm{g} / \mathrm{kg}$ dexmedetomidine or $2 \mu \mathrm{g} / \mathrm{kg}$ clonidine as adjuvants to epidural ropivacaine in lower abdominal surgeries. In terms of safety, the haemodynamic parameters and side effects are same in both the groups. Dexmedetomidine has a higher advantage than clonidine as it enables an earlier onset and establishment of sensory and motor block. 3/5 Wilson sedation scores was also significantly higher in Dexmedetomidine group.

In the present study the mean time of onset of sensory blockade and motor blockade with Dexmedetomidine is quicker than Clonidine and it is statistically significant (Table1\&2), which correlates with other studies.(11) The mean duration of motor blockade with Dexmedetomidine is more when compared to Clonidine and is statistical significant (Table-3). The duration of analgesia (Time from epidural injection to the time of administering rescue analgesic in the post-operative period) was prolonged and highest in Dexmedetomidine when compared to Clonidine and is highly statistically ssignificant (Table-4), which correlates with other studies.(12) Sedation level was assessed in both the groups by Wilson sedation scale. It is highly desirable to have patients with mild to moderate sedation during regional analgesia which is Wilson Grade 3, seen in more patients of Dexmedetomidine group when compared to Clonidine group (Table-7). In terms of side effects both these drugs were proved to be same. The side effects most commonly observed are hypotension \& bradycardia which are seen commonly with regional anaesthesia. In both the groups dry mouth and nausea is observed in the post-operative period but it is statistically non-significant (Table-6). None of the patient in either group had profound deep sedation or respiratory depression which correlates very well with other studies.(13) In the present study, hemodynamic monitoring was done 
continuously throughout the procedure. The vital parameters remained stable throughout the study period (Table-5) which ensure that $\alpha-2$ agonists provides hemodynamically stability in peri-operative and post-operative period.(14,15)

\section{CONCLUSION}

Dexmedetomidine acts as better neuraxial adjuvant when compared to Clonidine if given along with Ropivacaine in epidural anaesthesia, in terms of sedation and good analgesia throughout the intra and post-operative period. In terms of safety, the hemodynamic parameters and side effects are same in both the groups.

\section{REFERENCES}

[1] Sinha S, Mukerjee M, Chatterjee S, et al. Comparitive study of analgestic efficacy of ropivacaine with ropivacine plus dexmedetomidine for paravertebral block in unilateral renal surgery. Anaesth, Pain \& Intensive Care 2012;16(1):38-42.

[2] Barash PG, Cullen BF, Stoelting RK. Management of acute post-operative pain. $3^{\text {rd }}$ edn. Philadelphia, PA, USA: Lippincott - Raven Publications 1997: p. 1310.

[3] Dureja GP, Madan R, Kanl HL. Regional anaesthesia \& pain management: current perspectives. Section - 36 . Economics of Regional Anaesthesia Vs General Anaesthesia. 1st edn. New Delhi: Churchill Livingstone 2005: p. 278.

[4] Khangura N. Adjuvant agents in neuraxial blockade. Anaesthesia tutorial of the week 230. $4^{\text {th }}$ July 2011. p. 1-10.

[5] Scafati A. Analgesia and alpha agonists 2. Medens Rev 2004;4:7.

[6] Mauro VA, Brandão ST. Clonidine and dexmedetomidine through epidural route for postoperative analgesia and sedation in a colecistectomy. Rev Bras Anestesiol 2004;4:1-10.
[7] Bajwa SJS, Bajwa SK, Kaur J, et al. Dexmedetomidine \& clonidine in epidural anaesthesia: a comparative evaluation. Indian Journal of Anaesthesia 2011;55(2):116-21.

[8] Paris A, Tonner PH. Dexmedetomidine in anaesthesia. Curr Opin Anaesthesiol 2005;18(4):412-8.

[9] Scheinin M, Pihlavisto M. Molecular pharmacology of alpha 2 -adrenoceptor agonists. Baillièe's Clin Anaesth 2000;14:247-60.

[10] Correa-Sales C, Rabin BC, Maze M. A hypnotic response to dexmedetomidine, an alpha-2 agonist, is mediated in the locus coeruleus in rats. Anesthesiology 1992;76(6):948-52.

[11] Singh R, Shukla A. Randomized, controlled study to compare the effect of intrathecal clonidine \& dexmedetomidine on sensory analgesia \& motor block of hyperbaric bupivacaine. Indian Journal of Fundamental Applied Life Sciences 2012;2(4):24-33. http:/www.cibtech.org/j/s.htm

[12] Farmery AD, Wilson-MacDonald J. The analgesic effect of epidural clonidine after spinal surgery: a randomized placebo-controlled trial. Anesth Analg 2009;108(2):631-4.

[13] Milligan KR, Convery PN, Weir P, et al. The efficacy and safety of epidural infusions of levobupivacaine with and without clonidine for postoperative pain relief in patients undergoing total hip replacement. Anesth Analg 2000;91(2):393-7.

[14] Taittonen MT, Kirvelä OA, Aantaa R, et al. Effect of clonidine and dexmedetomidine premedication on perioperative oxygen consumption and haemodynamic state. Br J Anaesth 1997;78(4):400-6.

[15] Cortinez LI, Hsu YW, Sum-Ping ST, et al. Dexmedetomidine pharmacodynamics: Part II: crossover comparison of the analgesic effect of dexmedetomidine and remifentanil in healthy volunteers. Anesthesiology 2004;101(5):1077-83. 